\title{
Uso da barra transpalatina no controle da rotação da mandíbula
}

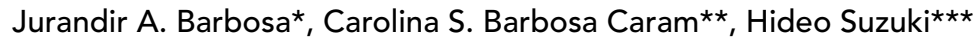

\begin{abstract}
Resumo
$\mathrm{Na}$ maioria dos pacientes na fase de dentição mista, com um certo grau de mordida aberta acompanhado de deglutição atípica ou algum mau hábito, observamos que o processo dentoalveolar superior está aumentado no sentido vertical. O uso da BTP nos molares superiores nestes casos, com a alça central colocada numa altura suficiente para, durante a deglutição, exercer alguma pressão sobre o dorso da língua, tem se mostrado de grande valia, notando-se como resultado uma restrição do crescimento do processo dentoalveolar no sentido vertical. Este resultado evita o deslocamento dentário no sentido vertical podendo até provocar movimento efetivo de intrusão dos molares com conseqüente mudança do eixo de crescimento com rotação da mandíbula no sentido anti-horário.
\end{abstract}

Palavras-chave: Controle vertical. Processo dentoalveolar. Barra transpalatina. Intrusão.

Má oclusão de Classe II.

\section{INTRODUÇÃO}

O sucesso do tratamento ortodôntico, em boa parte, está na dependência da correta interpretação e utilização dos efeitos do crescimento no complexo craniomandibular. Para sermos capazes de adaptar o tratamento ortodôntico ao processo de crescimento, devemos respeitar as relações entre as direções de deslocamento e as diferentes unidades faciais. A harmonia da face está na dependência da direção do movimento da sínfise mandibular relativo ao restante da face.

Se os fatores de crescimento das fossas mandibulares e dos côndilos forem mantidos em um nível constante, os componentes verticais da maxila mais os processos alveolares superior e inferior, influenciarão fortemente o deslocamento para frente e para baixo da sínfise mandibular e, com isso, a sua posição ântero-posterior. Assim sendo, quando o crescimento vertical, tanto da maxila como dos processos alveolares, forem maiores que o crescimento da fossa mandibular e côndilo, o eixo facial terá uma rotação no sentido horário, aumentando assim a altura facial inferior e, quando for ao contrário, teremos uma rotação no sentido anti-horário com conseqüente diminuição da altura facial inferior.

Segundo Stöckli e Teuscher ${ }^{17,18}$, a maxila cresce verticalmente, em média, $0,7 \mathrm{~mm} /$ ano e o processo dentoalveolar 0,9mm/ano (Fig. 1).

\footnotetext{
* Mestrado em Ortodontia pela USP-Bauru. Professor Pesquisador do Programa do Centro de Pesquisa São Leopoldo Mandic Campinas. Professor Coordenador do curso de Especialização em Ortodontia da ACDC - Campinas. Doutorando em Ortodontia pela São Leopoldo Mandic - Campinas.

** Mestrado em Ortodontia pela São Leopoldo Mandic - Campinas. Professora Pesquisadora do Programa do Centro de Pesquisa São Leopoldo Mandic - Campinas. Doutoranda em Ortodontia pela São Leopoldo Mandic - Campinas.

*** Mestrado em Ortodontia pela São Leopoldo Mandic - Campinas. Professor Pesquisador do Programa do Centro de Pesquisa São Leopoldo Mandic - Campinas. Professor Coordenador do curso de Especialização em Ortodontia na ABO - São Luiz/MA. Doutorando em Ortodontia pela São Leopoldo Mandic - Campinas.
} 
Introduzida por Goshgarian (apud McNAMARA, BRUDON ${ }^{8}$, 1995) a BTP tem sido comumente usada com a finalidade de controle vertical do processo dentoalveolar superior. Como resultado, McNamara Jr. ${ }^{13}$ diz que há uma efetiva intrusão dos molares, pela pressão que a língua exerce sobre a BTP (Fig. 2), conseqüentemente, o eixo facial tende a fechar, diminuindo o AFAI e mudando espacialmente a mandíbula no sentido anti-horário, proporcionando maior equilíbrio da oclusão e principalmente da face.

Em nossa prática diária procuramos definir uma distância ideal da alça central ao palato que consiga o movimento de intrusão ou bloqueio do crescimento vertical do processo dentoalveolar. Esta distância deve ser suficiente para provocar a impressão da alça central sobre a língua (Fig. 3), já que há uma individualidade muito grande desta pressão.

\section{REVISÃO DE LITERATURA}

Cetlin e Hoeve ${ }^{5}$ sugerem que, para exercer a intrusão dos molares, a BTP deverá estar afastada do palato.

Roth $^{15,16}$ afirma que, para haver intrusão dos molares, a BTP deve estar afastada do palato de 6 a $8 \mathrm{~mm}$, permitindo assim uma pressão da língua contra ela.

McNamara Jr. e Brudon ${ }^{14}$ citam que a alça central da BTP deve estar voltada para mesial, posicionada na região do dorso da língua, proporcionando assim uma maior pressão lingual.

Cetlin ${ }^{6}$ disse que iremos observar pouca influência mecânica em função da direção da alça central para mesial ou para distal, podendo ter apenas uma leve pressão da língua mais para distal ou para mesial, não interferindo no movimento de intrusão dos molares. Sua indicação está em função do desconforto que possa provocar ao paciente, por isso sugerimos utilizar a alça voltada para mesial nos segundo molares superiores.

Lamons e Holmes ${ }^{11}$ constataram que, na maioria dos casos das más oclusões de Classe II, os primeiros molares superiores estão rotacionados para mesial.

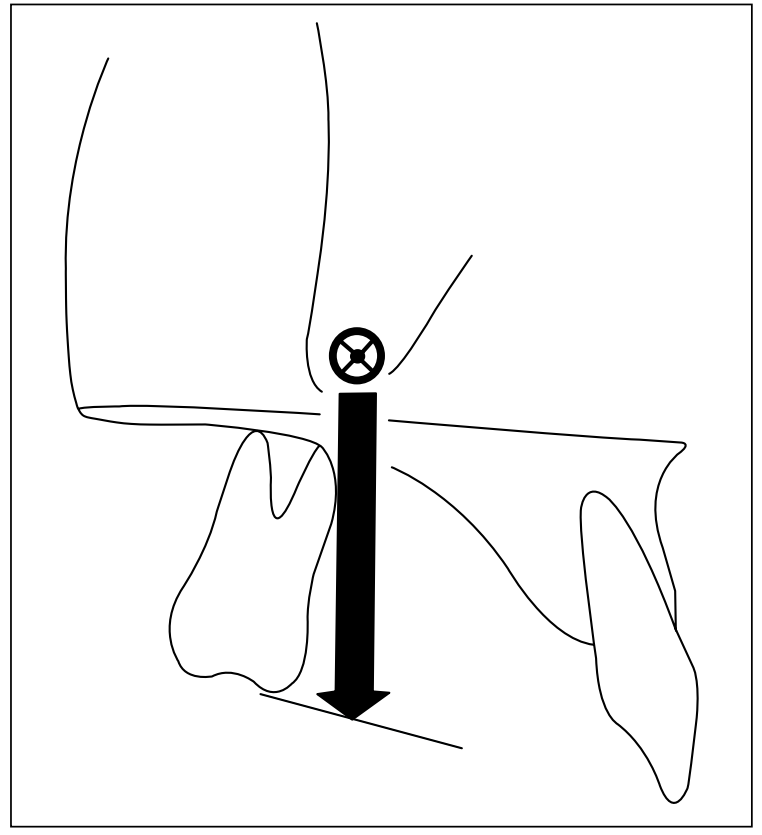

FIGURA 1 - Esquema do crescimento do processo dentoalveolar no sentido vertical $=0,9 \mathrm{~mm} / \mathrm{ano}$, em média.

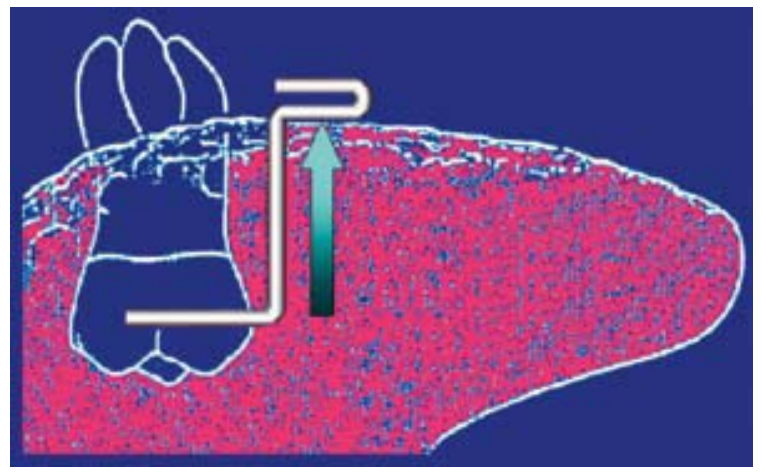

FIGURA 2 - Esquema de pressão da língua de encontro à alça central da BTP.

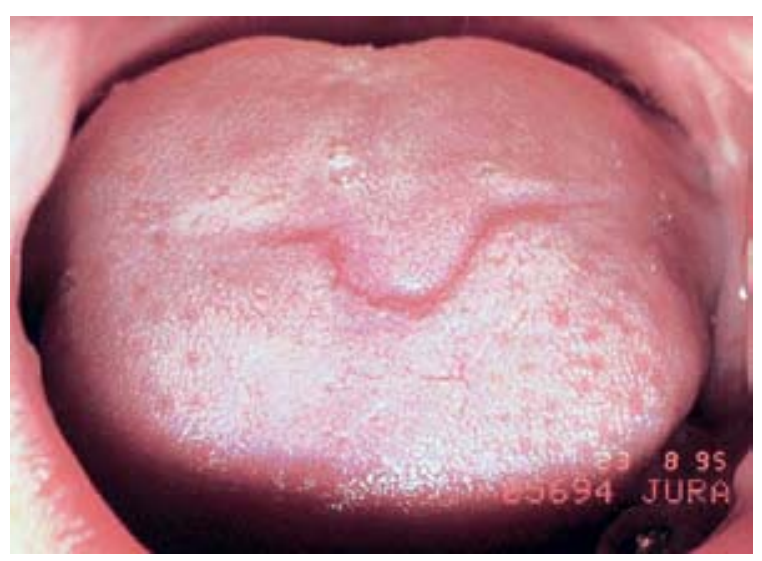

FIGURA 3 - Impressão da alça central sobre a língua. 
Kucher e Weiland ${ }^{10}$ descrevem que, após a distalização dos primeiros molares superiores, em muitos casos ocorre uma inclinação distovestibular excessiva do segundo molar, provocando muitas vezes interferência oclusal. Sua correção poderá ser feita com a utilização de uma barra transpalatina modificada.

Stockli e Teuscher ${ }^{17,18}$ descrevem a respeito de considerações básicas sobre o crescimento e desenvolvimento facial, comentando que fatores verticais exercem uma influência dominante no deslocamento ântero-posterior da sínfise e que o crescimento médio do processo alveolar superior é de aproximadamente $0,9 \mathrm{~mm} / \mathrm{ano}$ na região do primeiro molar permanente.

Zachrisson ${ }^{20}$ diz que, na correção da Classe II com maxila prognática, utiliza uma combinação de ancoragem extrabucal de tração alta e barra transpalatina com loop grande. Isto inibe o crescimento para baixo da face média e evita a erupção dos molares superiores.

Ferreira $^{7}$ avaliou funcionalmente a deglutição com a ajuda de uma fonoaudióloga em 20 pacientes, antes e após o uso da BTP, para verificar se a mesma alteraria o mecanismo funcional da deglutição. Concluiu que o padrão não se alterou, mudou apenas a memória proprioceptiva e da formação de uma nova imagem mental, ou seja, de um novo padrão proprioceptivo.

Suzuki ${ }^{19}$, em seu trabalho de mestrado, concluiu que o eixo $\mathrm{Y}$ de crescimento tem uma tendência a abrir quando a base anterior do crânio está aumentada e/ou a porcentagem de Jarabak diminuída.

Kanashiro e Fantini ${ }^{9}$ dizem que as barras transpalatinas são acessórios ortodônticos em evidência nos últimos tempos, por exibirem eficiência na produção e controle de diversos tipos de movimentos dos molares superiores, sem a necessidade de grande colaboração por parte do paciente. Descrevem que, quando as barras transpalatinas são ativadas, podem movimentar os molares nos três planos do espaço, promovendo rotação, expansão ou contração (movimentos de $1^{\mathrm{a}}$ ordem); inclina- ção mésio-distal, intrusão (movimentos de $2^{\mathrm{a}}$ ordem) e torque (movimentos de $3^{\mathrm{a}}$ ordem).

Marchi et al. ${ }^{12}$ teceram algumas considerações sobre a mecânica de Cetlin. Citam que na arcada superior o espaço é obtido por meio da barra transpalatina, aparelho removível e ancoragem extrabucal. Dizem que, como grande parte das más oclusões de Classe II apresentam rotação mesial dos primeiros molares superiores, a barra transpalatina é usada inicialmente para rotacionálos. Após a distalização dos molares com outros dispositivos, e obtido espaço no arco, é instalada uma barra transpalatina para manter a rotação dos molares e estabilizar a ancoragem.

Cardoso ${ }^{4}$, em sua dissertação de mestrado, concluiu que o padrão de crescimento apresentado pelo Grupo Face Longa foi vertical, com aumento da altura facial anterior inferior. Apresentou também um retrognatismo maxilar e mandibular, sendo essa característica mais acentuada no gênero feminino. As variáveis dentárias também se apresentaram alteradas, havendo uma excessiva extrusão dentária anterior e póstero-superior.

Barbosa ${ }^{2}$ diz que tem obtido excelentes resultados em pacientes na fase da dentadura mista com crescimento vertical do processo alveolar aumentado e, geralmente, com algum grau de mordida aberta e deglutição atípica. Com o uso da BTP, com a alça central mais baixa o suficiente para exercer alguma pressão sobre o dorso da língua durante a deglutição, obtemos alterações no crescimento e desta forma mudamos espacialmente a mandíbula no sentido anti-horário, proporcionando maior equilíbrio da oclusão e principalmente da face.

Barbosa et $\mathrm{al}^{3}{ }^{3}$ relatam que a BTP é efetiva quando necessitamos de restrição do crescimento vertical do processo dentoalveolar, possibilitando rotação mandibular.

\section{Análise do tecido mole}

A análise facial é a chave do diagnóstico e de nossas decisões terapêuticas. Além de outros parâmetros para avaliar o tecido mole, seguimos a 
Linha Subnasal Vertical, de acordo com Ayala e Gutierrez ${ }^{1}$ (Fig. 4), para avaliar a posição sagital do lábio superior, lábio inferior e o mento.

No momento de julgar clinicamente o perfil de nossos pacientes, a avaliação deve ser realizada visualizando, fundamentalmente, do nariz para baixo. Se a relação entre maxila e mandibula for harmoniosa, o perfil será julgado como esteticamente agradável, independente da posição da maxila com respeito à base do crânio ou aos pontos glabela ou násio.

Com esta finalidade, escolhemos o ponto subnasal, do qual traçamos uma linha vertical, perpendicular à linha do horizonte ou plano horizontal verdadeiro (PHV), denominada Linha Subnasal Vertical (LSV). Esta linha apresenta as seguintes vantagens:

1) o ponto de origem é perto das estruturas que queremos avaliar, quer dizer, o terço inferior da face;

2) este ponto se vê menos afetado por mudanças de posição ou tamanho das estruturas a que pertencem, como sucede na maioria dos planos de referência estética utilizados. Por exemplo, a avaliação efetuada mediante o plano E de Ricketts ou a linha $\mathrm{H}$ de Holdaway pode ser influenciada pelo tamanho do nariz, posição da mandíbula ou projeção sagital do pogônio mole.

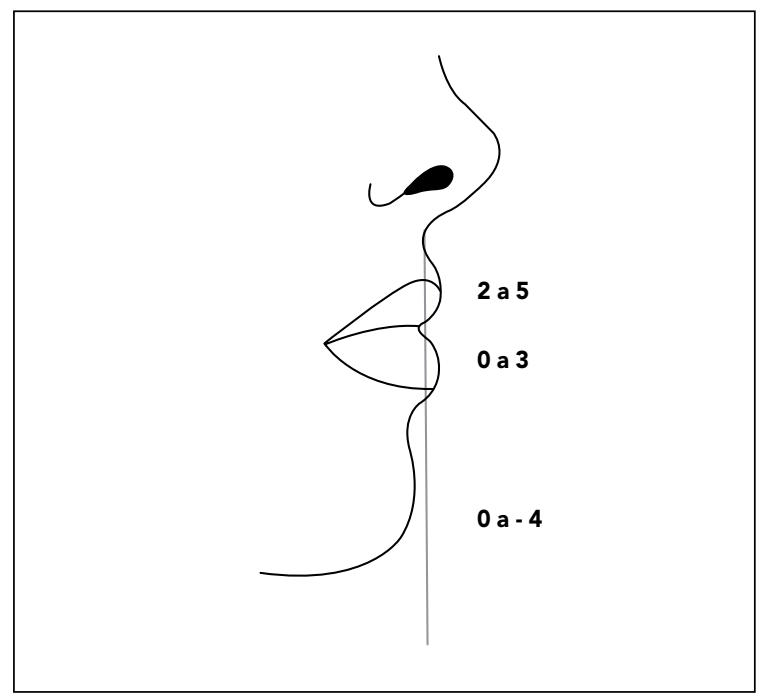

FIGURA 4 - Padrão para análise do tecido mole com a vertical subnasal ${ }^{1}$.

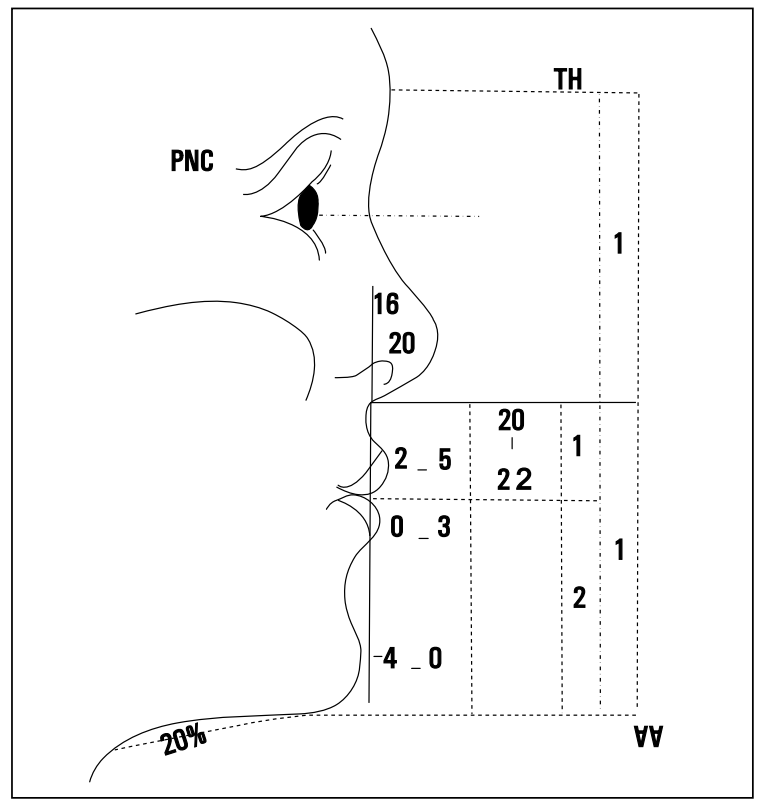

FIGURA 5 - Análise facial total sagital e vertical.

As proporções verticais da análise facial estão representadas na figura 5 .

\section{CASO CLÍNICO 1}

Características gerais

Paciente F. B., 7 anos e 9 meses, gênero feminino com deglutição atípica.

\section{Características dentárias}

Classe II, Div. I, mordida aberta anterior, atresia maxilar e rotação mesial dos primeiros molares superior e trespasse horizontal (Fig. 6A, B, C, D, E).

\section{Características cefalométricas}

Padrão Mesofacial com índice Vert. de +0.09 segundo Ricketts (Fig. 7A); porcentagem de Jarabak 60.6\%; base anterior do crânio com $61 \mathrm{~mm}$ (Fig. 7B).

\section{Características faciais}

De acordo com o protocolo de Ayala e Gutierrez ${ }^{1}$ (Fig.4), notamos na telerradiografia inicial a posição do mento mole com -6 portanto com uma retrusão mandibular (Fig. 7B) ${ }^{4}$. 


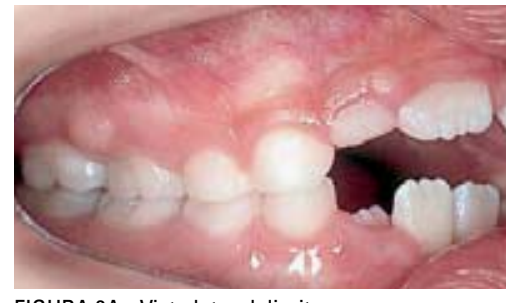

FIGURA 6A - Vista lateral direita.

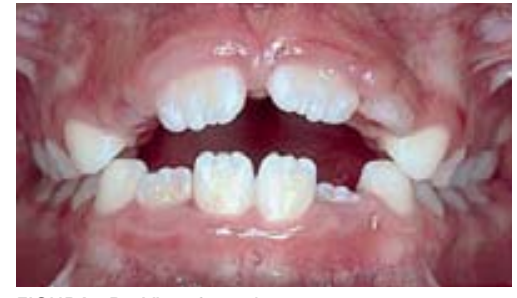

FIGURA 6B - Vista frontal.

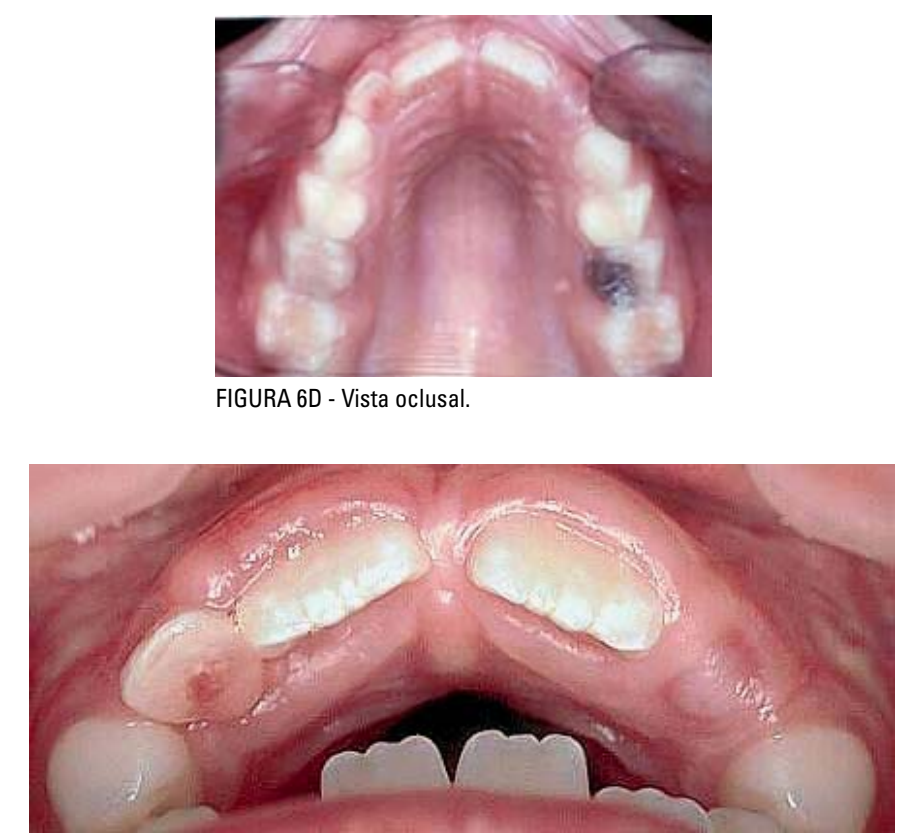

FIGURA 6D - Vista oclusal.

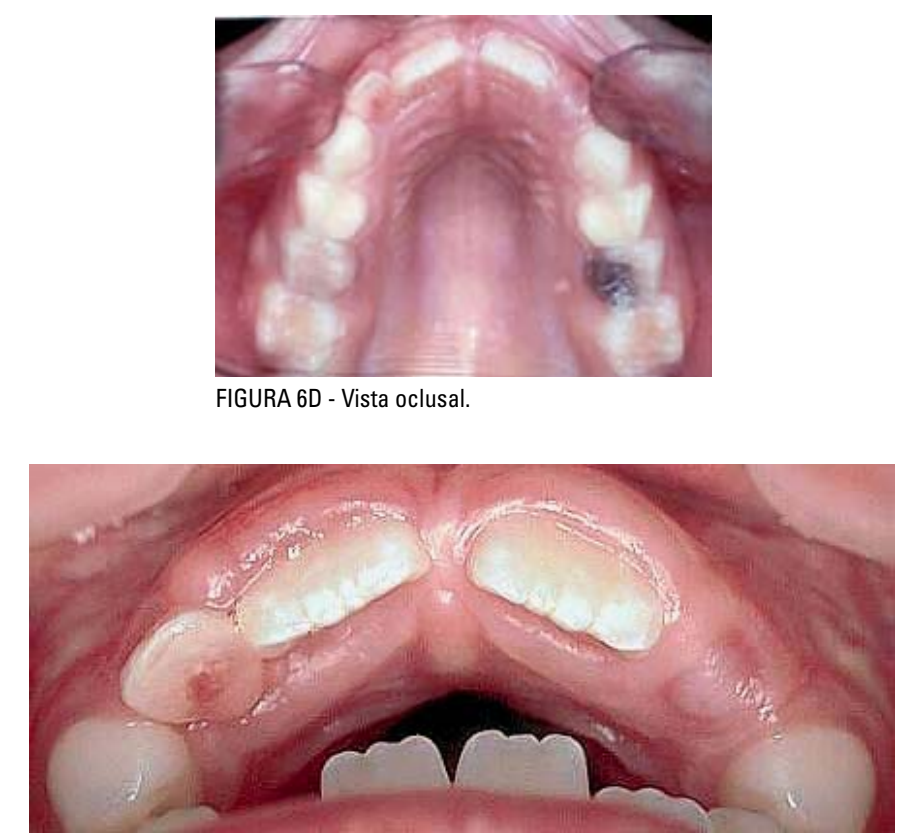

FIGURA 6E - Trespasse.

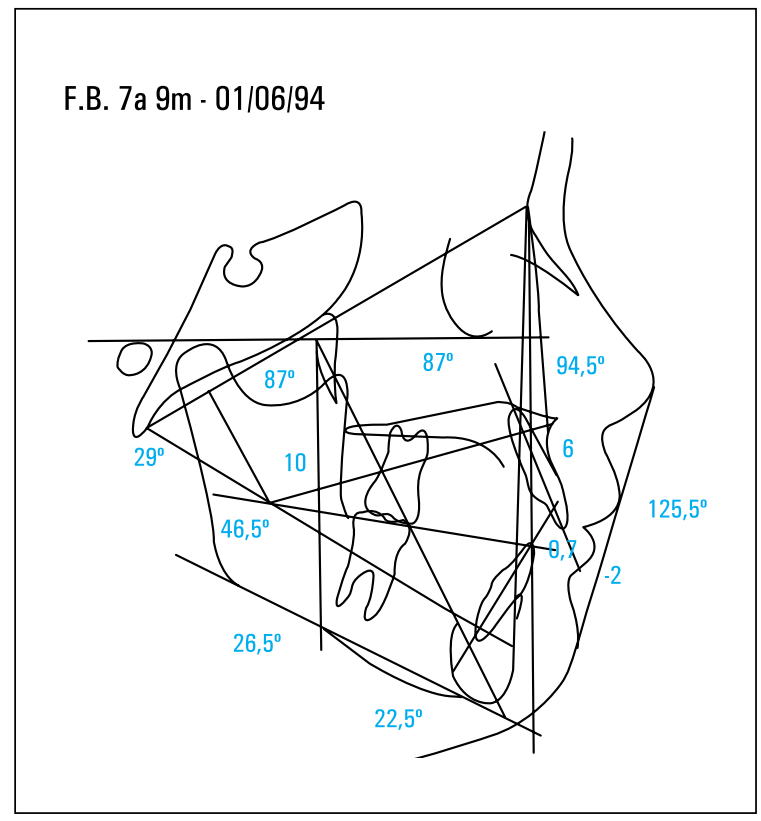

FIGURA 7A - Traçado de Ricketts.

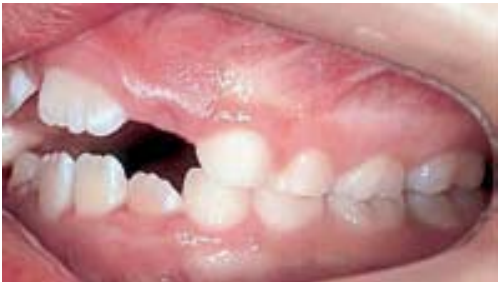

FIGURA 6C - Vista lateral esquerda.

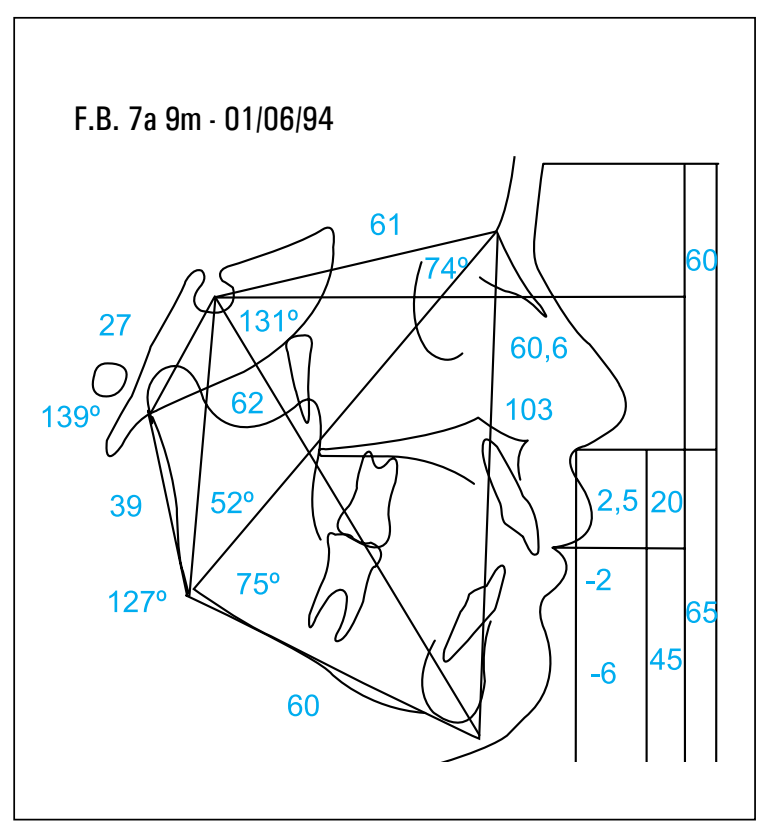

FIGURA 7B - Características cefalométricas e análise do tecido mole. 


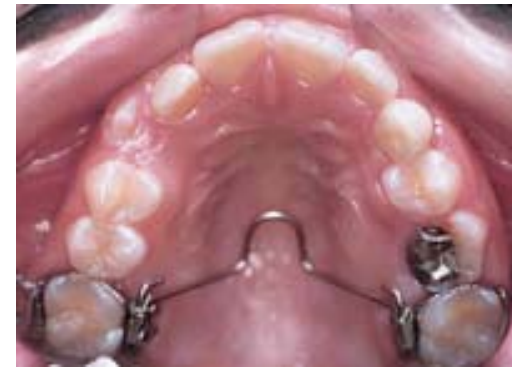

FIGURA 8 - Vista oclusal.

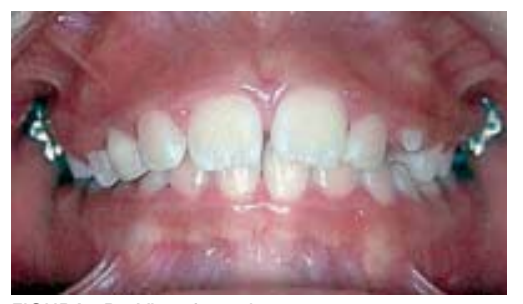

FIGURA 9B - Vista frontal.

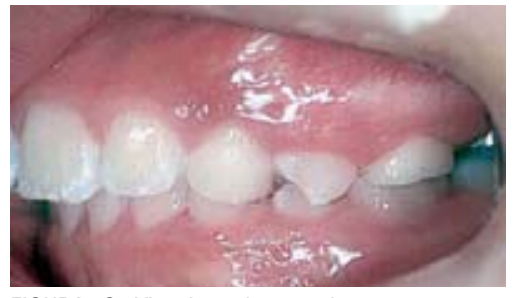

FIGURA 9C - Vista lateral esquerda.

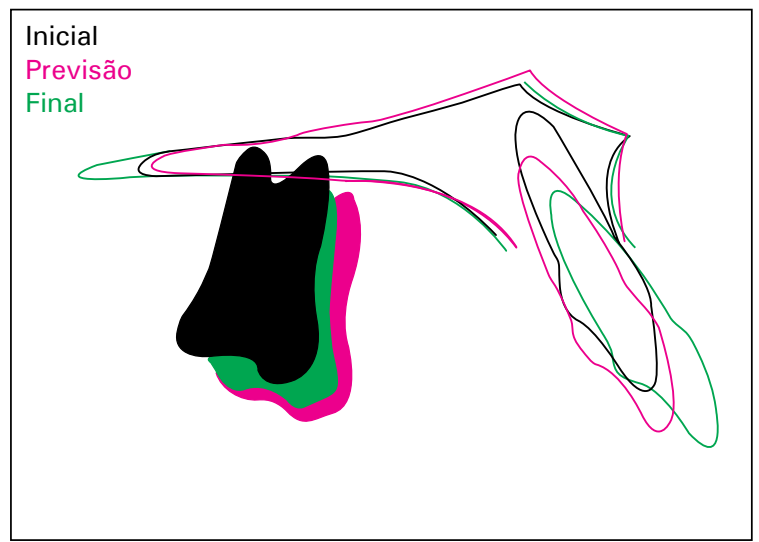

FIGURA 10A - Sobreposição previsão, inicial e final.

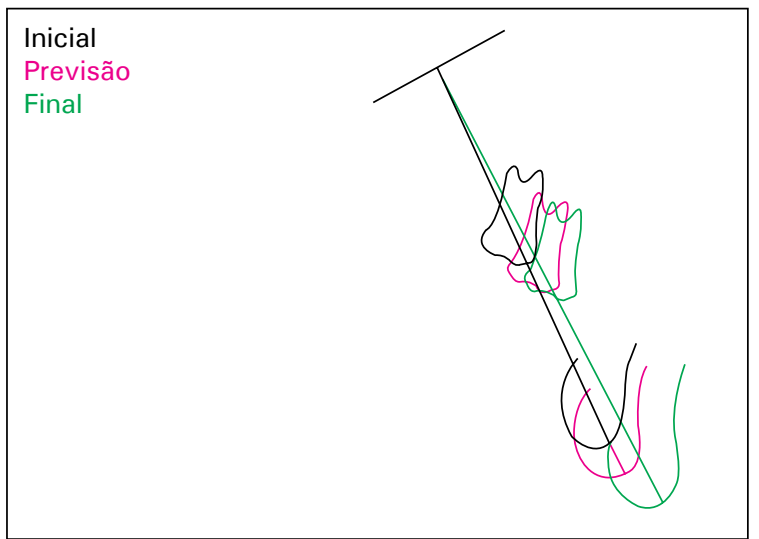

FIGURA 10B - Sobreposição previsão, inicial e final.

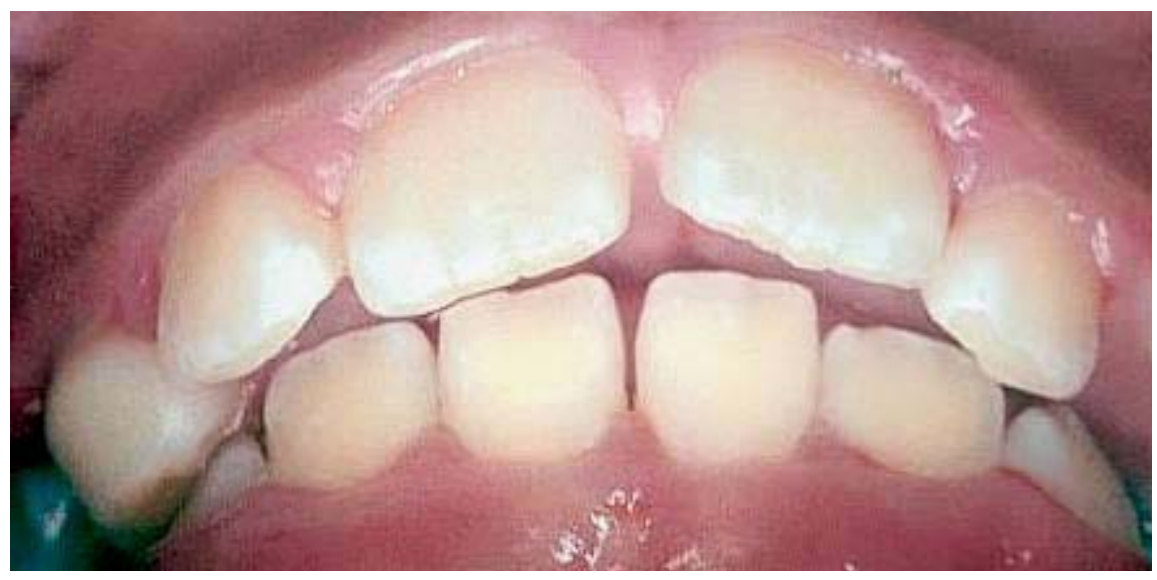

FIGURA 11 - Trespasse. 


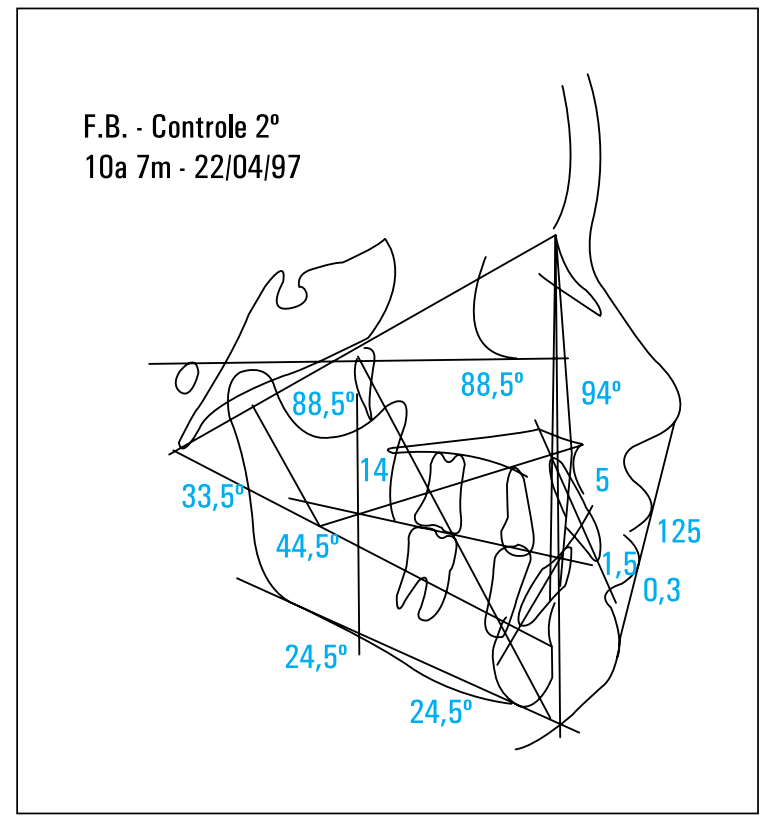

FIGURA 12A - Traçado final de Ricketts.

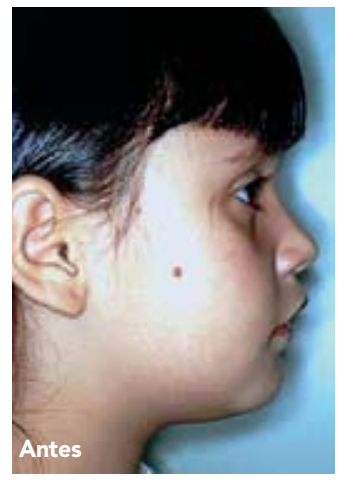

FIGURA 13A - Perfil.

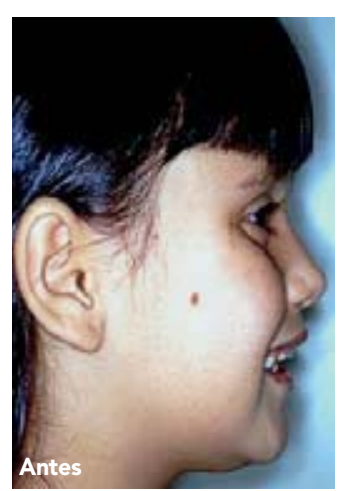

FIGURA 13C - Perfil sorrindo.
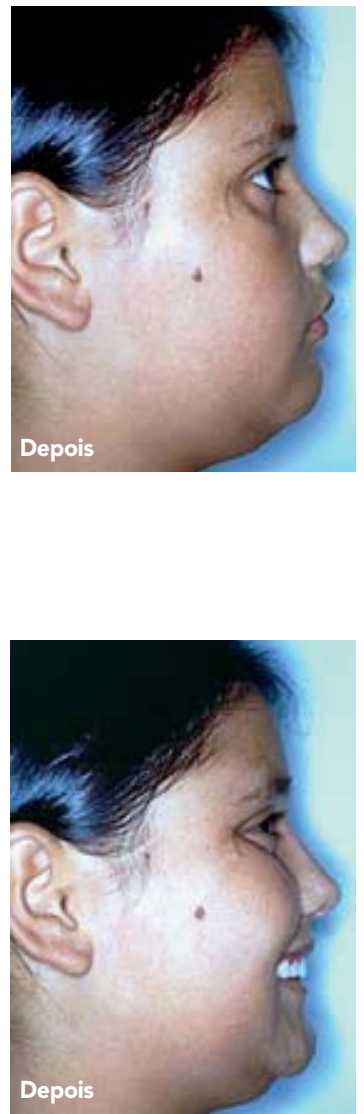

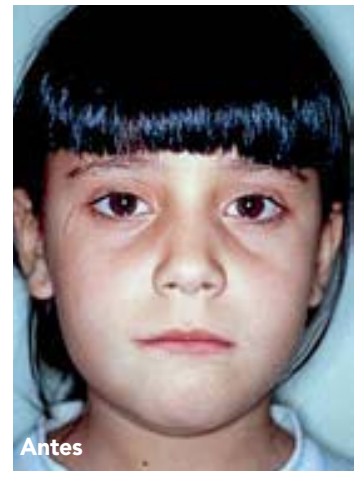

FIGURA 13B - Frontal.

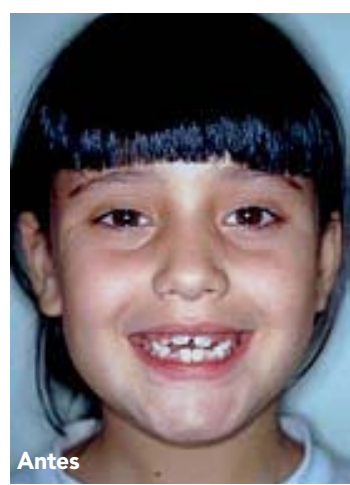

FIGURA 13D - Frontal sorrindo.
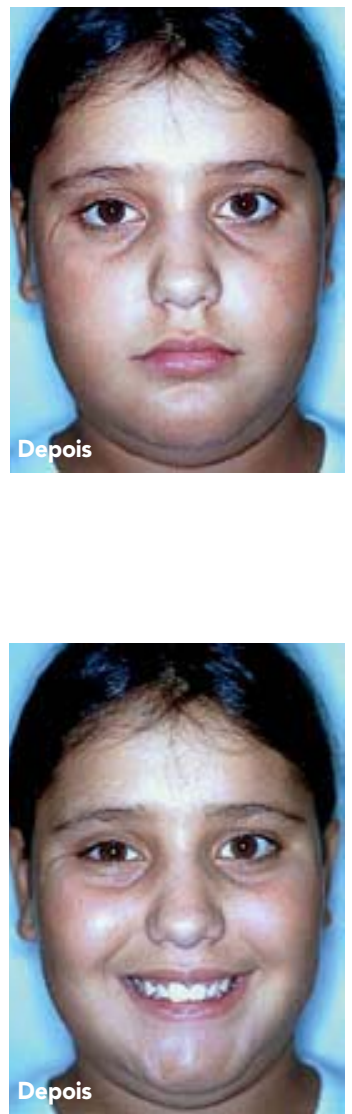


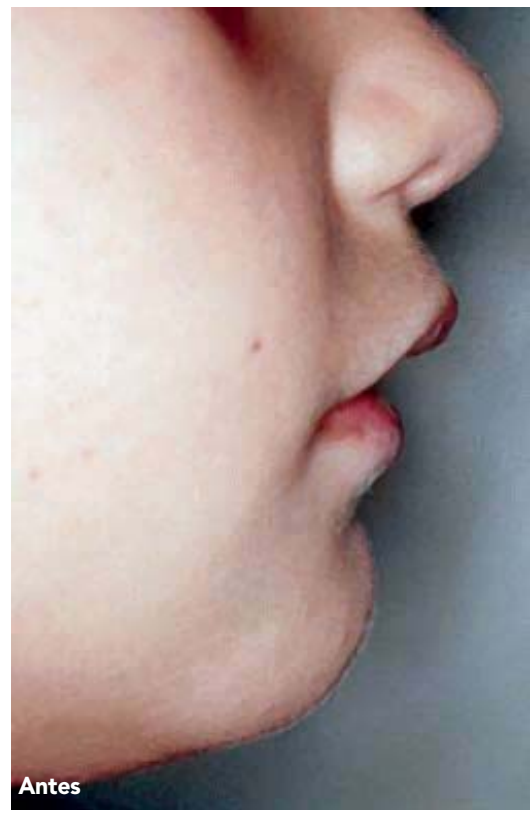

FIGURA 13E - Perfil aproximado.

\section{Mecânica utilizada}

Barra transpalatina adaptada nos primeiros molares superiores através de bandas com tubo palatino com a finalidade de expandir e girar os primeiros molares superiores, mas principalmente para bloquear o crescimento do processo dentoalveolar no sentido vertical, utilizando a pressão da língua sobre a mesma. A BTP foi usada por um período de 31 meses. A distância da alça central ao palato era de aproximadamente $3 \mathrm{~mm}$, o suficiente para provocar pressão da língua, confirmada pelo sinal da alça central sobre a mesma.

Após este período a BTP foi removida e seguimos observando a paciente a cada 6 meses, até a erupção dos segundos molares para avaliação da necessidade da colocação de aparelho fixo.

\section{Resultados}

1) Rotação, ganho de espaço e expansão do arco (Fig. 8).

2) Intrusão dos primeiros molares e diminuição da Classe II pela rotação (Fig. 9A). Foi utilizado o recurso da sobreposição do traçado inicial (preto);

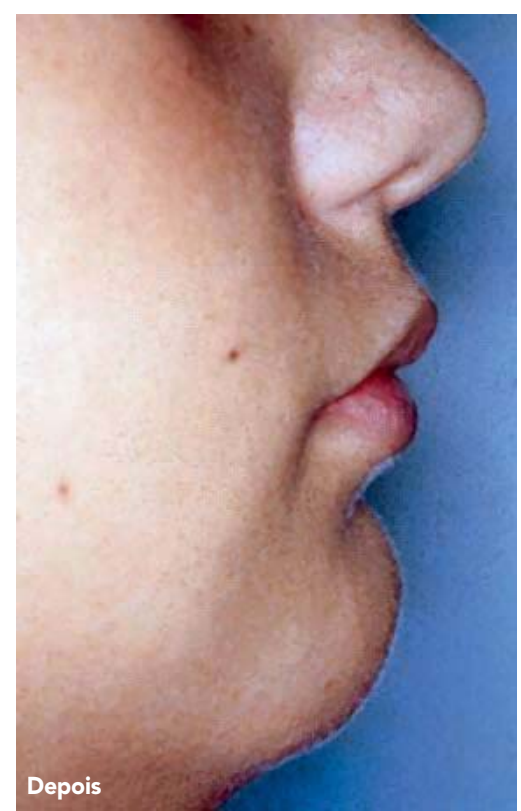

previsão de crescimento (vermelho) e traçado final pós-BTP (verde), para mostrar o resultado obtido com as mudanças no posicionamento do primeiro molar superior. Entre a posição final e da previsão existe uma diferença de aproximadamente $2 \mathrm{~mm}$, determinada pela ação da BTP contra o crescimento vertical do processo alveolar (Fig. 10A) que é descrito por Stockli e Teuscher ${ }^{17,18}$. Além da restrição do crescimento vertical do processo alveolar nota-se, na mesma figura, o movimento extrusivo dos dentes anteriores.

3) Na figura 10B nota-se a rotação da mandíbula no sentido anti-horário e fechamento do eixo facial, e também a diminuição da sobressaliência e fechamento da mordida aberta (Fig. 9B, 11)

4) $\mathrm{Na}$ cefalometria final de Ricketts temos o padrão braquifacial com Índice Vert. de $+0,52$ (Fig. 12A).

5) Análise do tecido mole pós-BTP, através da Vertical Subnasal (Fig.12B), confirma os resultados anteriores, com alteração principalmente no mento, melhorando consideravelmente a harmonia facial, mostrado antes e depois (Fig. 13A,B,C, D, E). 


\section{CASO CLÍNICO 2}

\section{Características gerais}

Paciente M. B., 9 anos, gênero feminino, presença de hábito de sucção de chupeta e deglutição atípica.

\section{Características dentárias}

Classe II, divisão 1, subdivisão lado direito, mordida cruzada posterior lado direito, mordida aberta anterior. (Fig. 14A, B, C). Primeiros molares superiores com rotação mesial (Fig. 15).

\section{Características cefalométricas}

Padrão mesofacial, com índice Vert. de $+0,80$, segundo Ricketts (Fig.16), e porcentagem de Jarabak 58,9 \%, base anterior do crânio aumentada sugerindo uma tendência para abrir o eixo facial durante o crescimento de acordo com as conclu- sões de Suzuki ${ }^{19}$ (Fig. 17).

\section{Características faciais}

Retrusão mandibular, observada na análise facial, de acordo com Ayala e Gutierrez ${ }^{1}$, com $-8 \mathrm{~mm}$ no mento e $-3 \mathrm{~mm}$ no lábio inferior (Fig. 17).

\section{Mecânica utilizada}

Inicialmente usamos um arco em $\mathrm{W}$ para descruzar a mordida do lado direito e em seguida colocamos a barra transpalatina com a finalidade de manter o descruzamento, corrigir a rotação e intruir os primeiros molares superiores, bloqueando o crescimento do processo dentoalveolar. A BTP foi adaptada aos tubos palatino das bandas nos primeiros molares permanente e utilizada por 23 meses. Durante os primeiros seis meses o controle foi feito mensalmente e, após este período, de 3 a 6 meses.

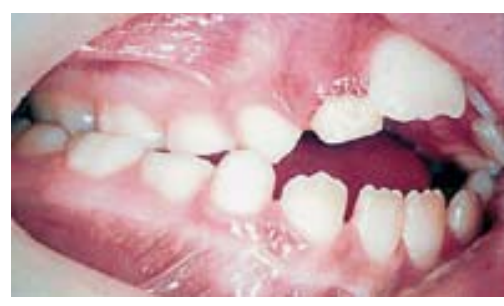

FIGURA 14A - Classe II lado direito. Mordida cruzada.

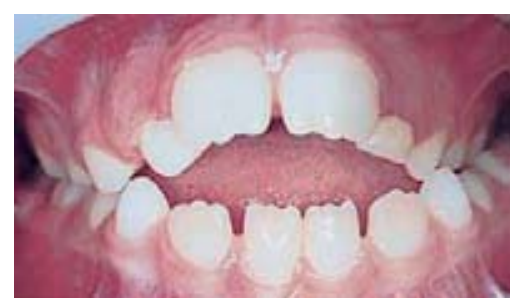

FIGURA 14B - Vista frontal. Mordida aberta.

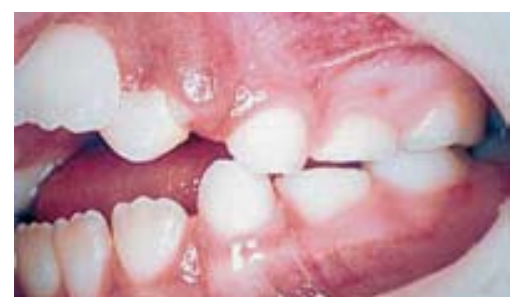

FIGURA 14C - Classe I - lado esquerdo.

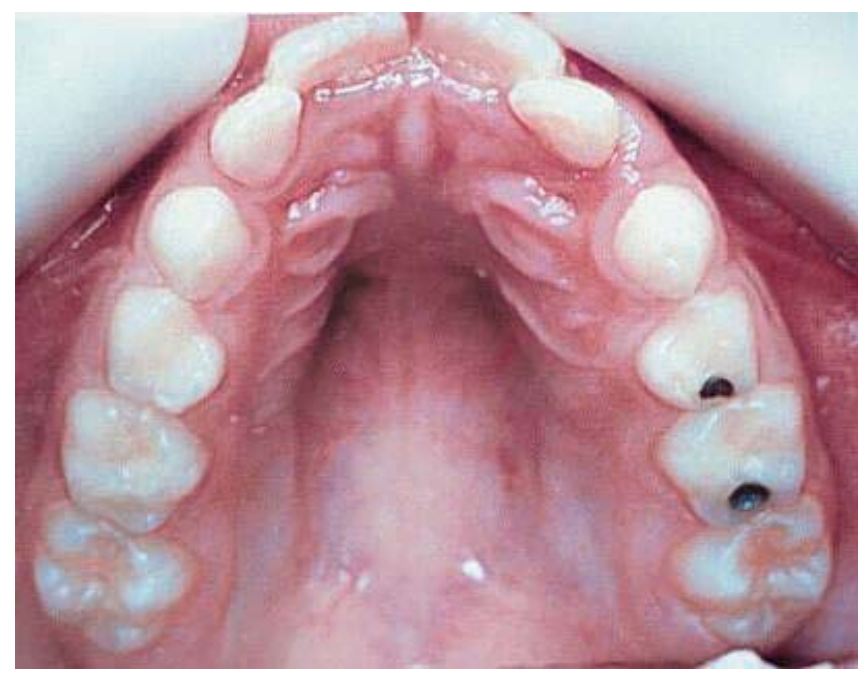

FIGURA 15 - Rotação mesial dos molares. 


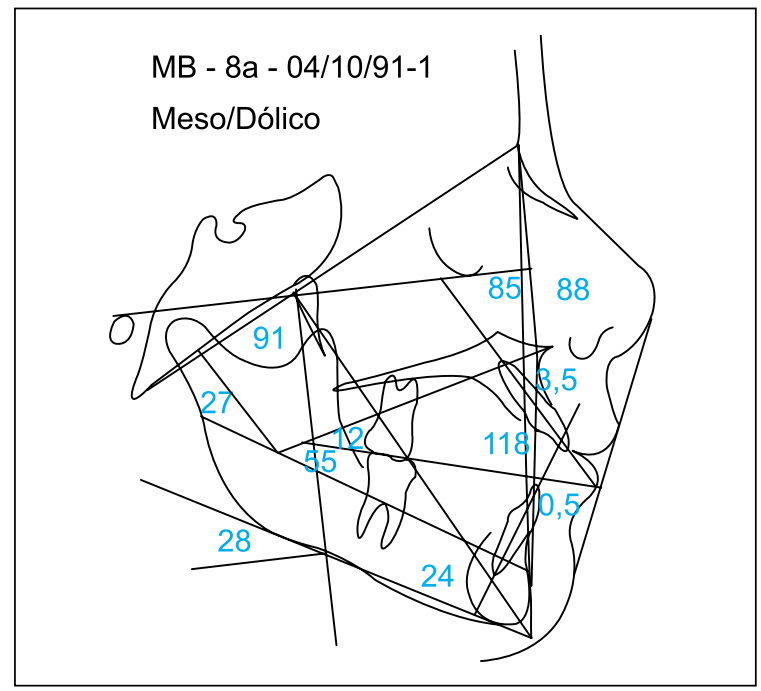

FIGURA 16 - Traçado de Ricketts.

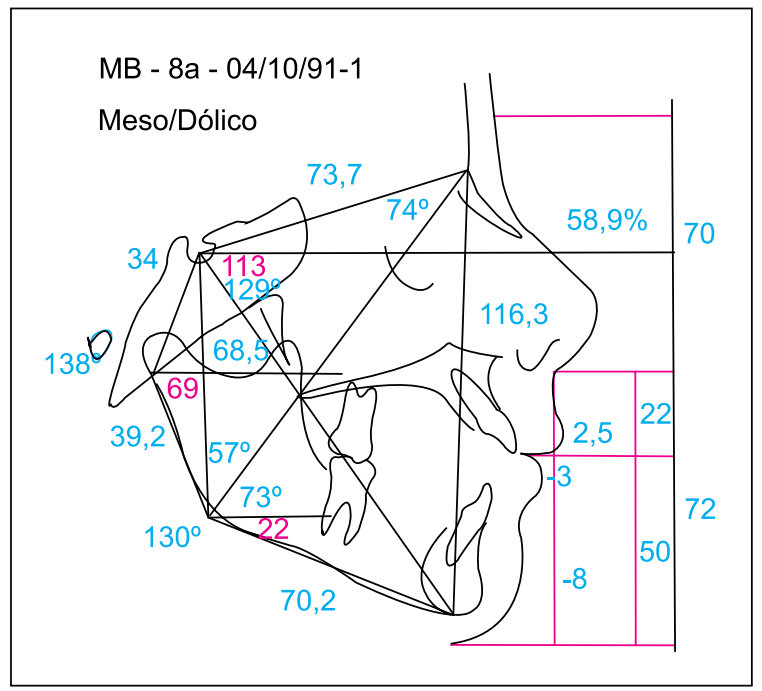

FIGURA 17 - Traçado de Jarabak com modificações de Suzuki.

\section{Resultados}

1) Descruzamento da mordida (lado direito) e manutenção com a BTP (Fig. 18).

2) Expansão, rotação e ganho de espaço no arco (Fig. 19).

3) Intrusão dos primeiros molares superiores, observada pela distância do plano palatal até a cúspide mesial dos molares diminuindo em $2 \mathrm{~mm}$ na $2^{\text {a }}$ telerradiografia (Fig. 20, 21).

4) Apesar da análise cefalométrica inicial mos-

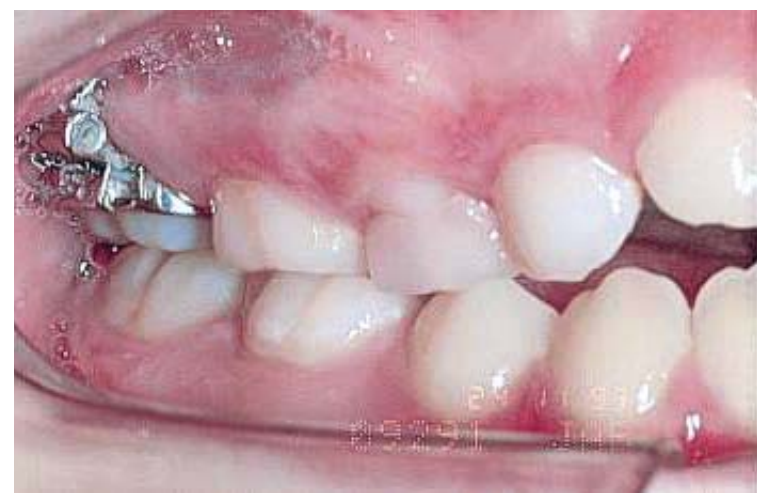

FIGURA 18 - Descruzamento da mordida. trar a base anterior do crânio aumentada, sugerindo abertura do eixo facial, dando como resultado um crescimento no sentido horário, as sobreposições do traçado inicial (preto); previsão de crescimento (vermelho) e pós-BTP (verde), mostram o giro da mandíbula no sentido anti-horário, diminuindo a sobressaliência e mordida aberta, comprovado pelo fechamento do eixo facial (Fig. $22,23,24,25)$. A figura 27 mostra a sobreposição inicial e pós-BTP com rotação da mandíbula no

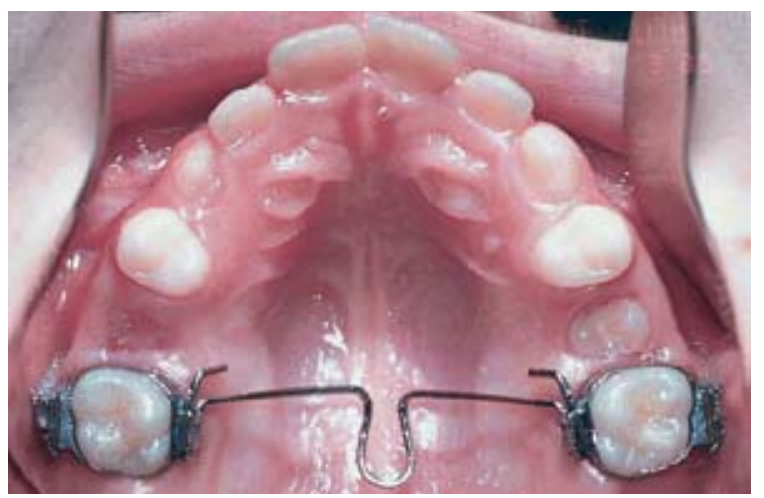

FIGURA 19 - Rotação distal dos molares. 


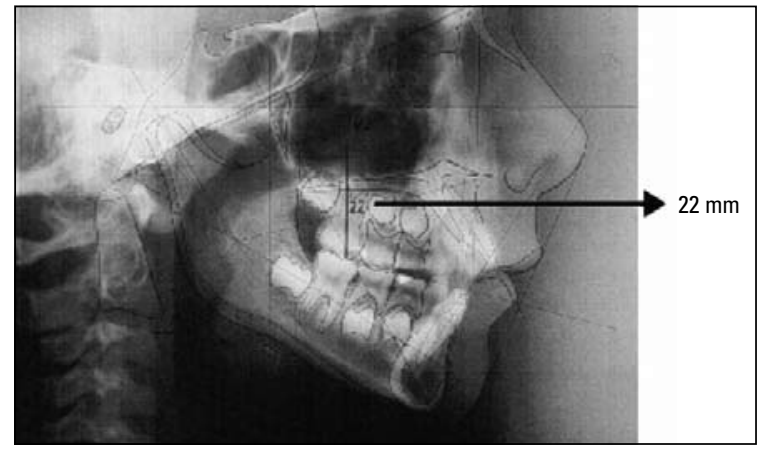

FIGURA 20 - Inicial.

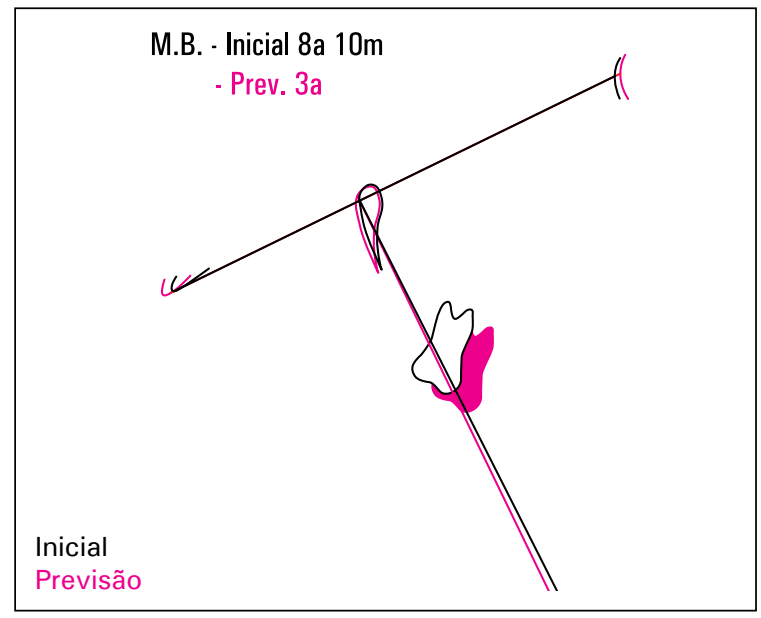

FIGURA 22 - Pós-BTP com intrusão.

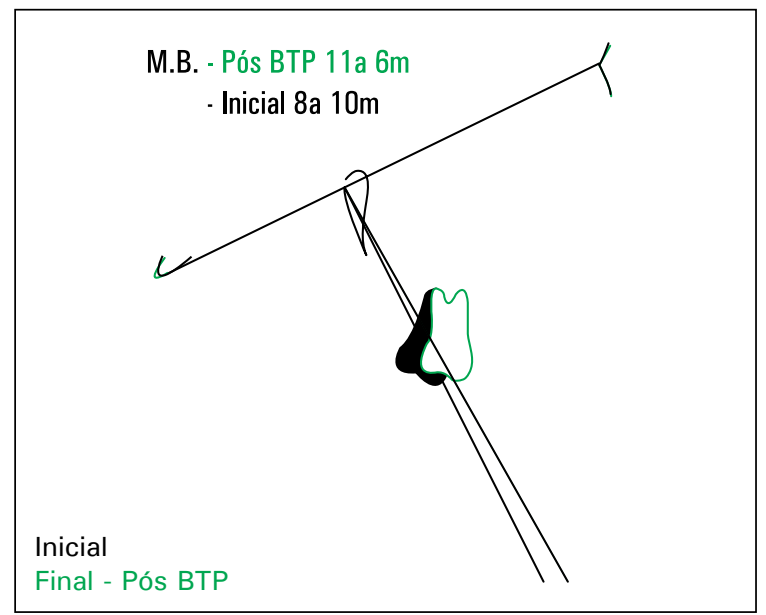

FIGURA 24 - Sobreposição inicial e pós-BTP.

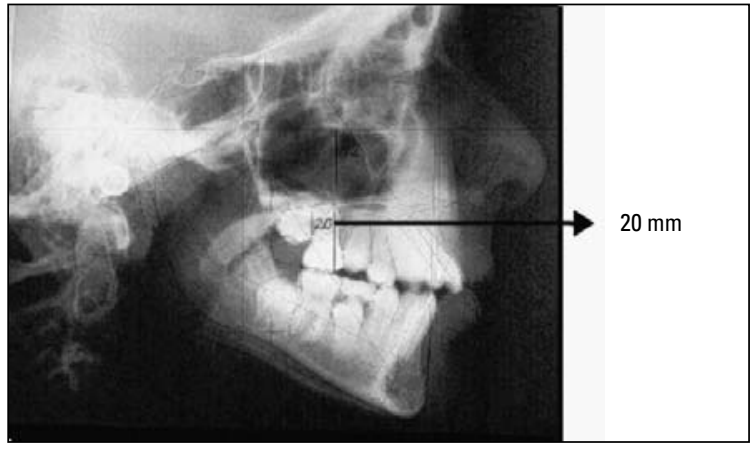

FIGURA 21 - Pós-BTP com intrusão.

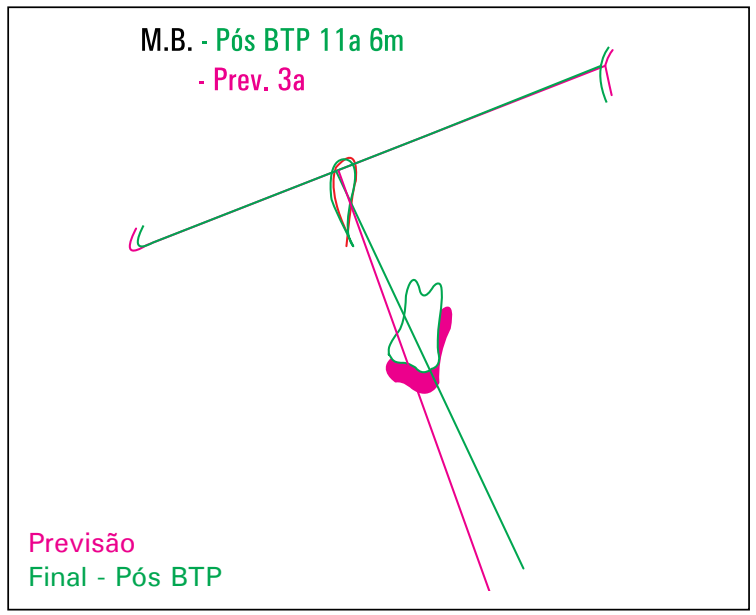

FIGURA 23 - Sobreposição previsão e pós-BTP.

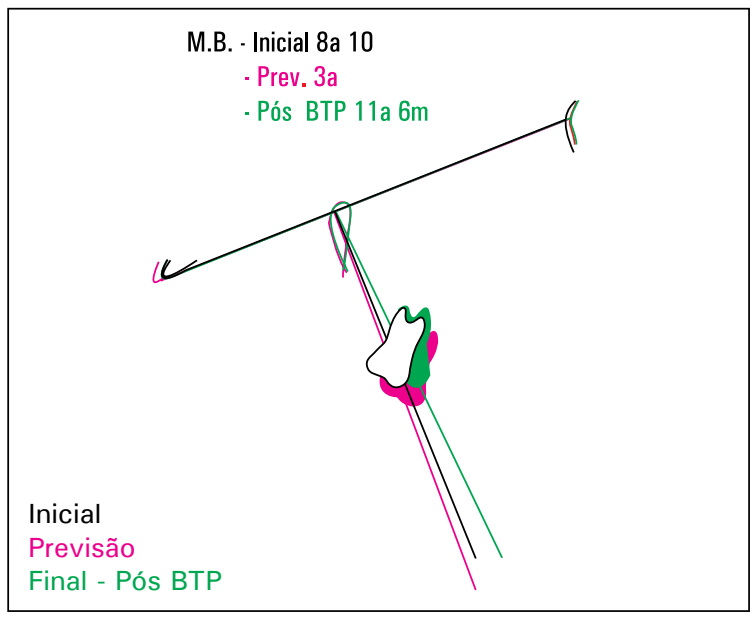

FIGURA 25 - Sobreposição inicial, previsão e pós-BTP. 


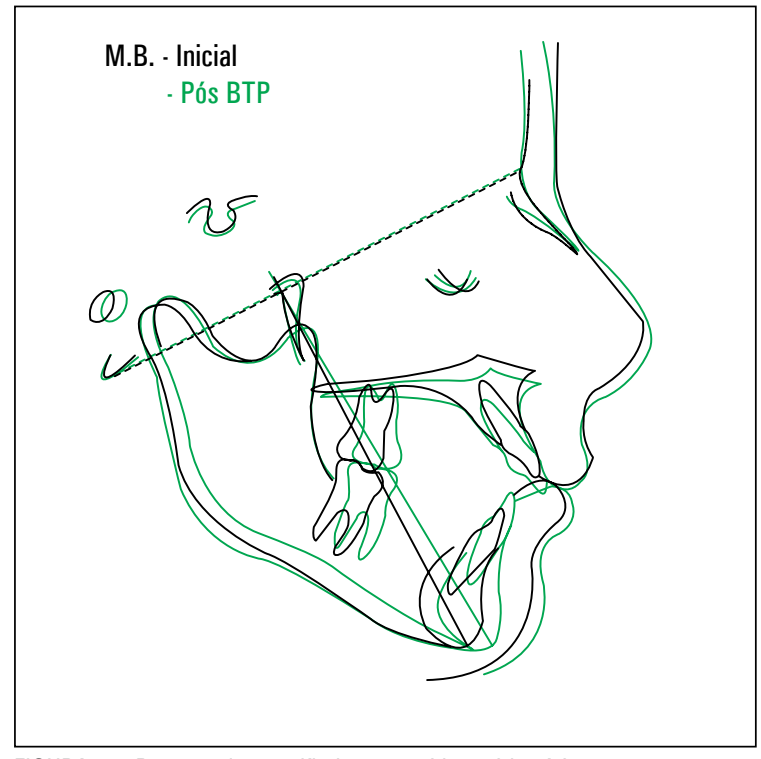

FIGURA 26 - Rotação da mandíbula no sentido anti-horário.

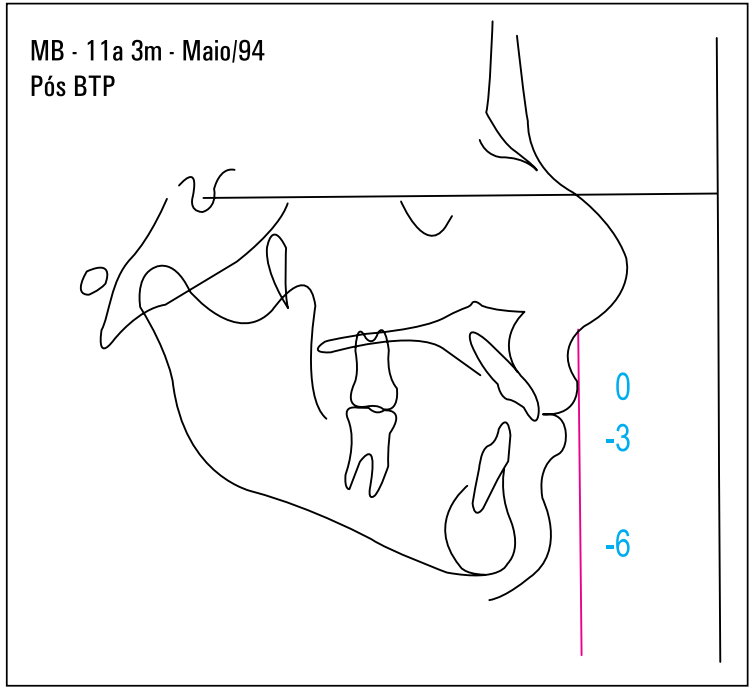

FIGURA 28 - Análise do tecido mole com a vertical sub-nasal.

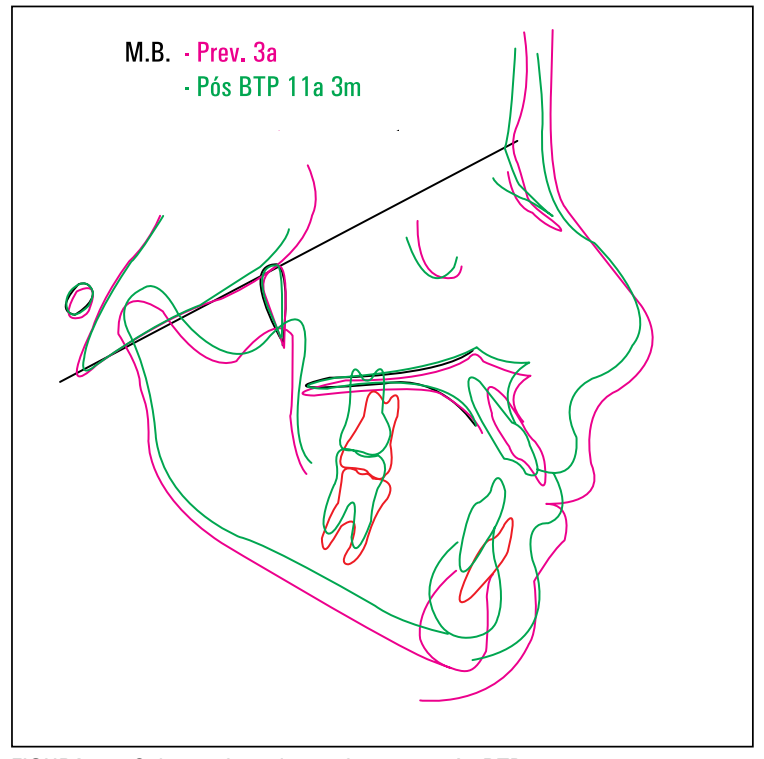

FIGURA 27 - Sobreposição da previsão com pós-BTP.

sentido anti horário, porém de uma forma parcial, enquanto na figura 28 , com sobreposição da previsão de crescimento e pós-BTP, acreditamos ser o resultado mais próximo do real.

5) $\mathrm{Na}$ análise do tecido mole através da Vertical Subnasal, houve a confirmação dos resultados anteriores com a melhora na relação entre os lábios superior e inferior e também na posição do mento (Fig. 28).

6) Após 23 meses notamos a melhora no relacionamento dos molares assim como da região anterior (Fig. 29A, B, C).

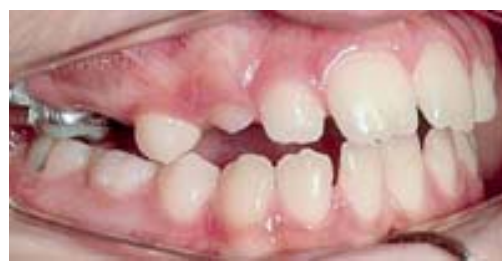

FIGURA 29A - Vista lateral direita.

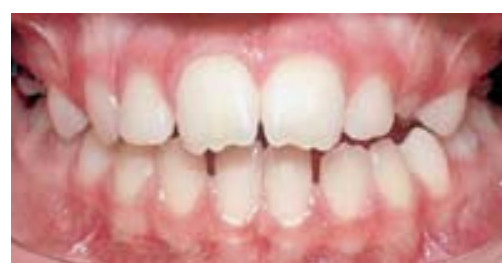

FIGURA 29B - Vista frontal, correção da mordida aberta.

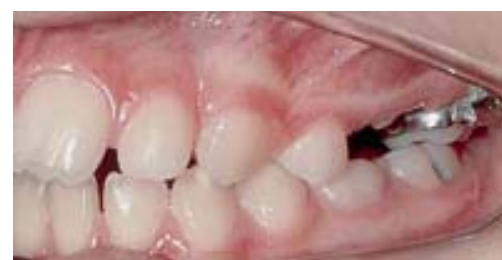

FIGURA 29C - Vista lateral esquerda. 


\section{CASO CLINICO 3}

\section{Características gerais}

Paciente F. G. P., com 7a. 8m., gênero feminino.

\section{Características dentárias}

Mordida aberta anterior; sobressaliência; apinhamento anterior superior e inferior e atresia maxilar (Fig. 30B, D); mordida cruzada posterior lado direito (Fig. 30A); Classe II, Div. I, subdivisão lado esquerdo (Fig. 30C) e primeiros molares superiores com rotação mesial (Fig. 30E).

\section{Características faciais}

Analisando a foto na vista frontal observa- mos uma pequena assimetria facial (Fig. 31A); navista lateral (Fig. 31B, C) nota-se um ângulo nasolabial dentro da norma e mostra nitidamente uma retrusão mandibular, confirmada pela análise de tecidos moles na cefalometria lateral, com $-2,5 \mathrm{~mm}$ no lábio inferior e $-9 \mathrm{~mm}$ no mento (Fig. 32B). Nesta figura podemos notar também o aumento da altura facial inferior na análise do tecido mole.

\section{Características cefalométricas}

Análise cefalométrica segundo Ricketts mostra um padrão mesofacial; indice Vert. de +0.17 (Fig. 32A); porcentagem de Jarabak de 55,8\% e modificações de Suzuki (Fig. 32B).

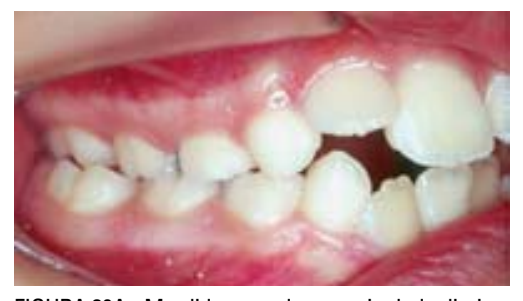

FIGURA 30A - Mordida cruzada posterior lado direito.

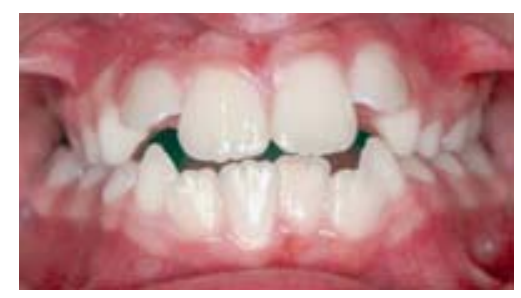

FIGURA 30B - Vista frontal.

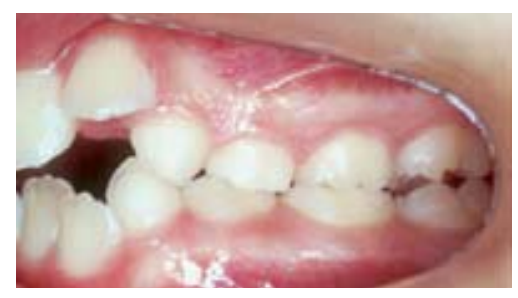

FIGURA 30C - Classe II lado esquerdo.

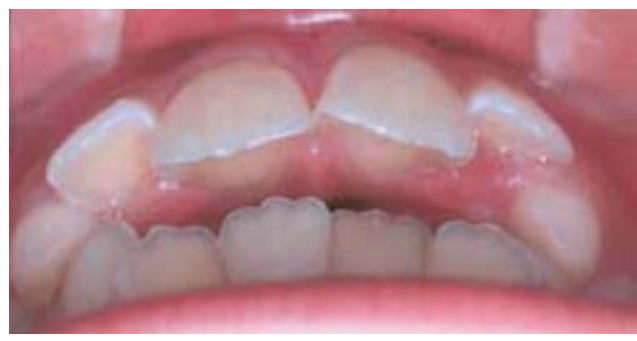

FIGURA 30D - Trespasse.

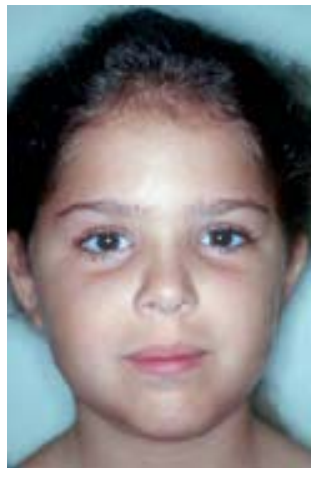

FIGURA 31A - Vista frontal.

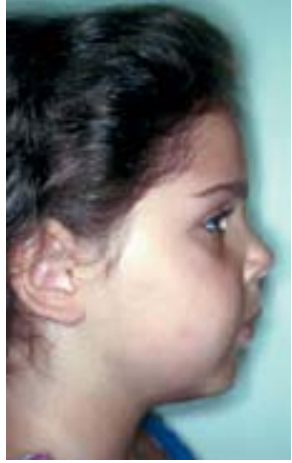

FIGURA 31B - Vista lateral.

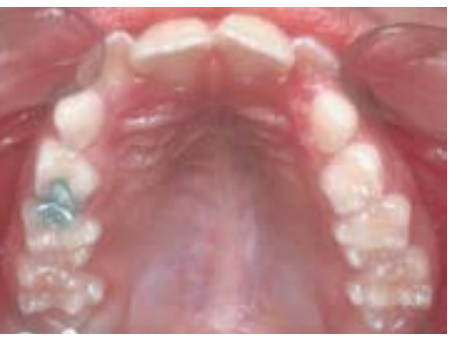

FIGURA 30E - Vista oclusal, primeiros molares com rotação mesial. 


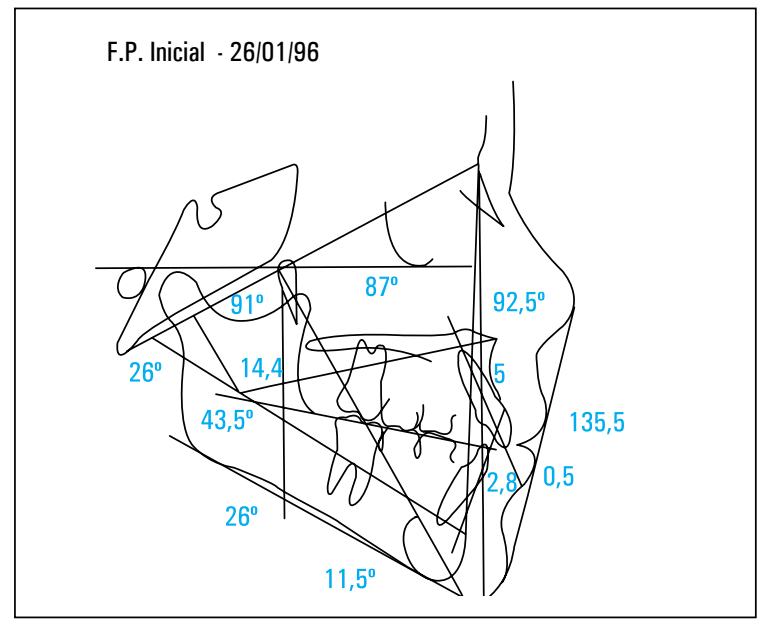

FIGURA 32A - Traçado inicial de Ricketts.

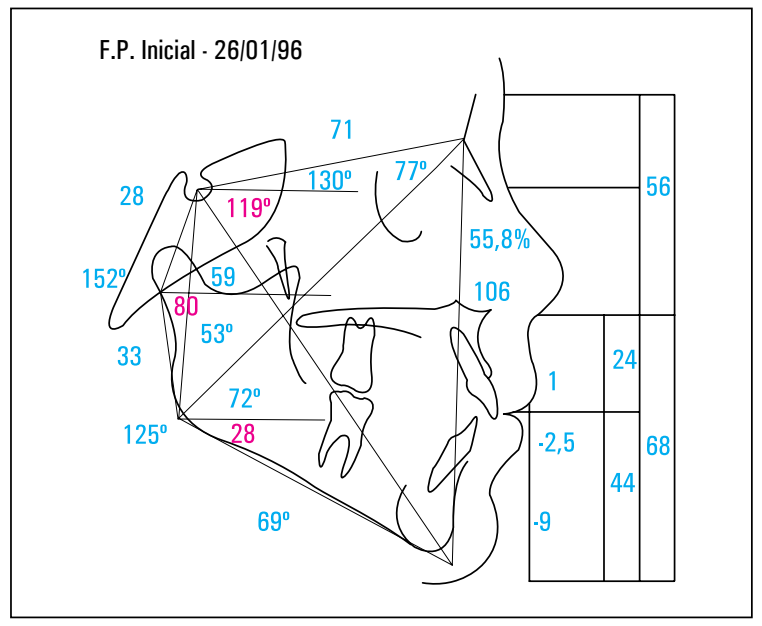

FIGURA 32B - Traçado inicial de Jarabak e análise dos tecidos moles.

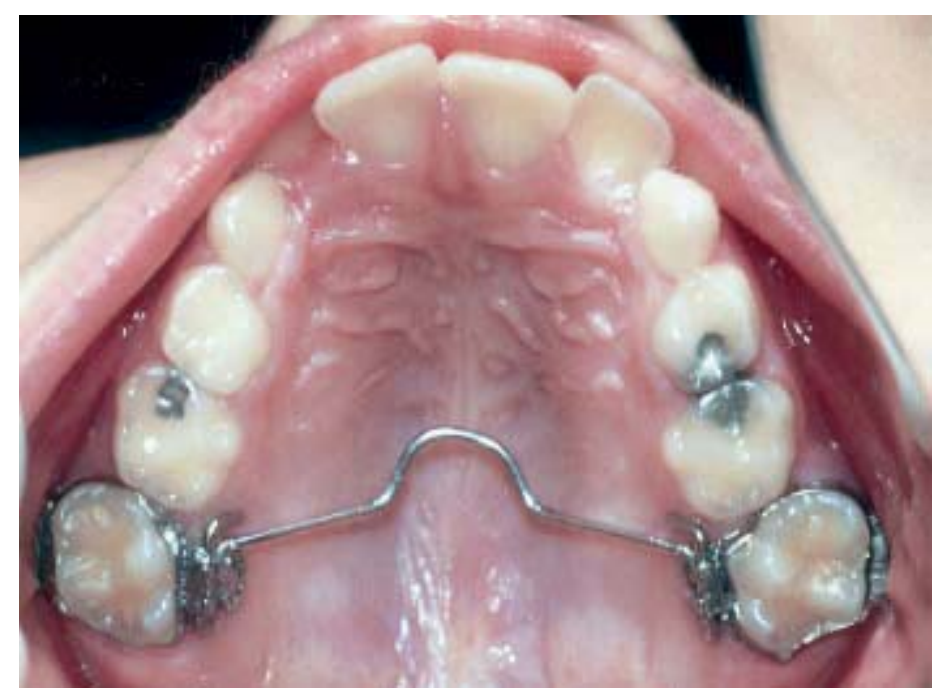

FIGURA 33 - Rotação distal dos molares.

\section{Mecânica utilizada}

Usou-se somente uma BTP adaptada aos primeiros molares superiores, com afastamento do palato o suficiente para provocar pressão da língua contra a alça central com a finalidade de bloquear o crescimento no sentido vertical do processo dentoalveolar ou até conseguir intrusão efetiva dos molares (Fig. 33). Foi usada durante 22 meses com controle mensal durante os primeiros 6 meses e, após este período, retornos entre 3 a 6 meses de intervalo.

\section{Resultados}

1) Rotação distal dos primeiros molares com ganho de espaço, descruzamento e manutenção dos resultados (Fig. 33).

2) Intrusão dos primeiros molares e correção da Classe II pela rotação (Fig. 34A, C). Foi utilizado o recurso da sobreposição do traçado inicial (preto); previsão de crescimento (vermelho) e traçado final pós-BTP (verde), para mostrar o resultado obtido com as mudanças no posicionamento vertical do 


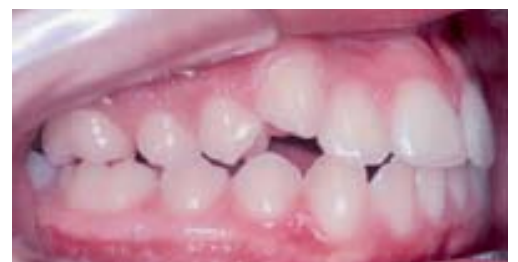

FIGURA 34A - Lado direito. Correção da Classe II.

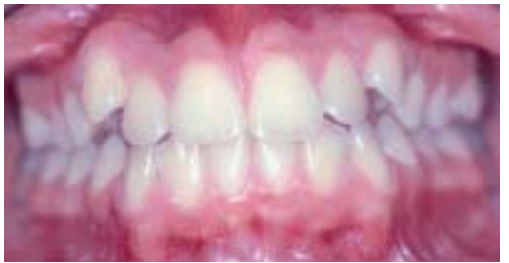

FIGURA 34B - Frontal com fechamento da mordida.

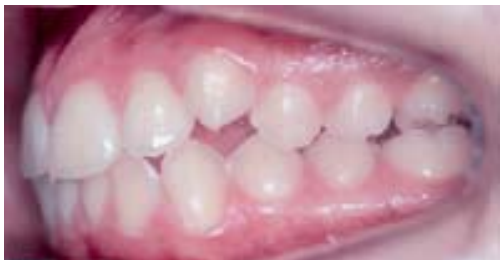

FIGURA 34C - Lado esquerdo. Correção da Classe II.

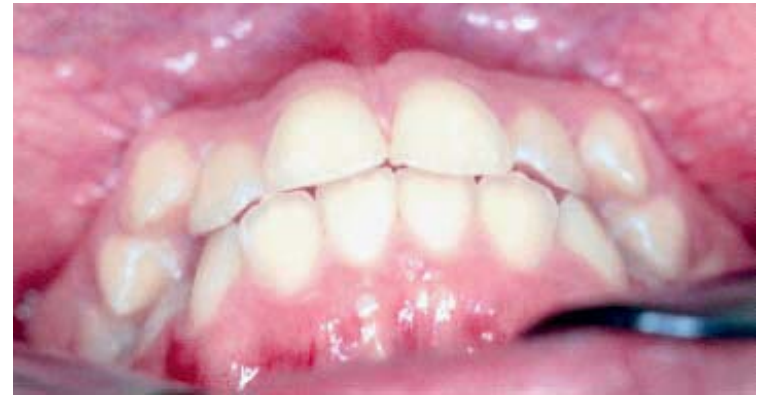

FIGURA 35 - Trespasse sem sobressaliência.

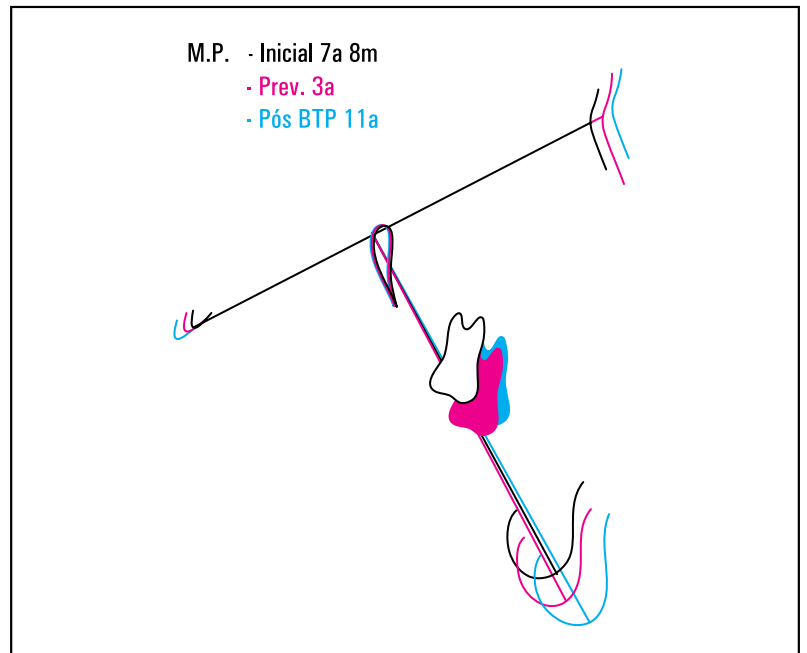

FIGURA 36 - Sobreposição inicial, previsão e pós-BTP.

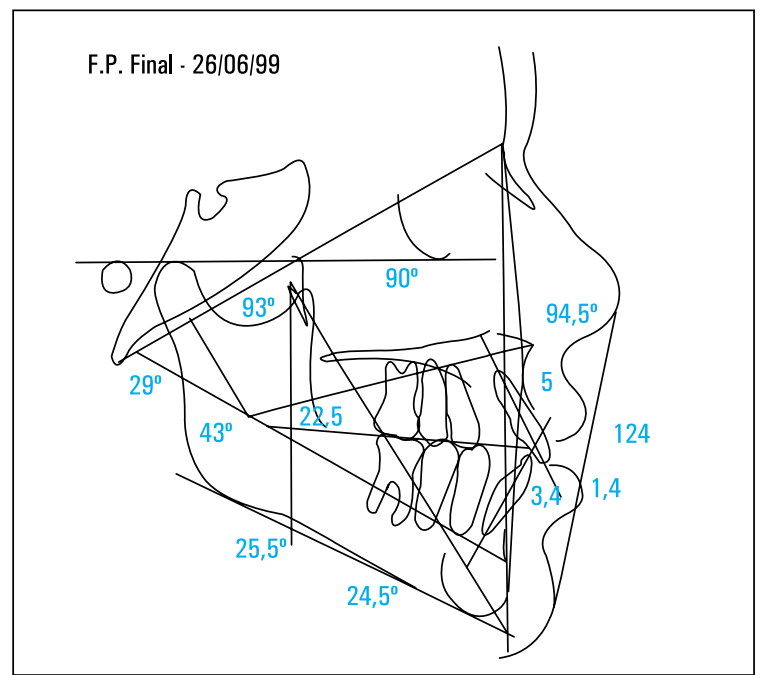

FIGURA 37A - Traçado de Ricketts.

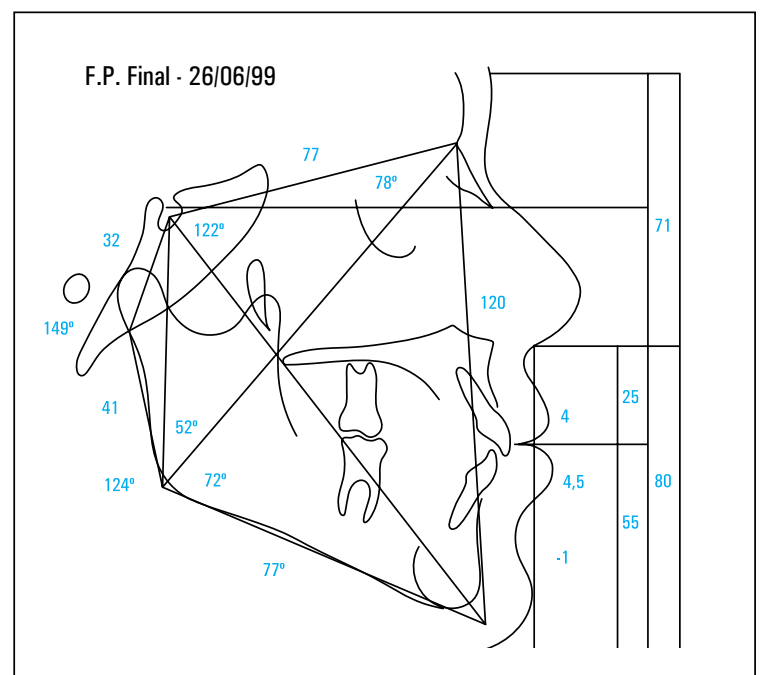

FIGURA 37B - Características cefalométricas finais e análise do tecido mole. 


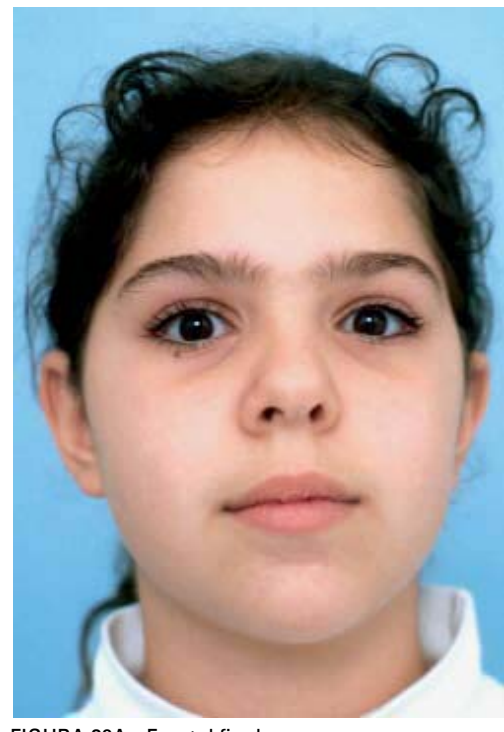

FIGURA 38A - Frontal final.

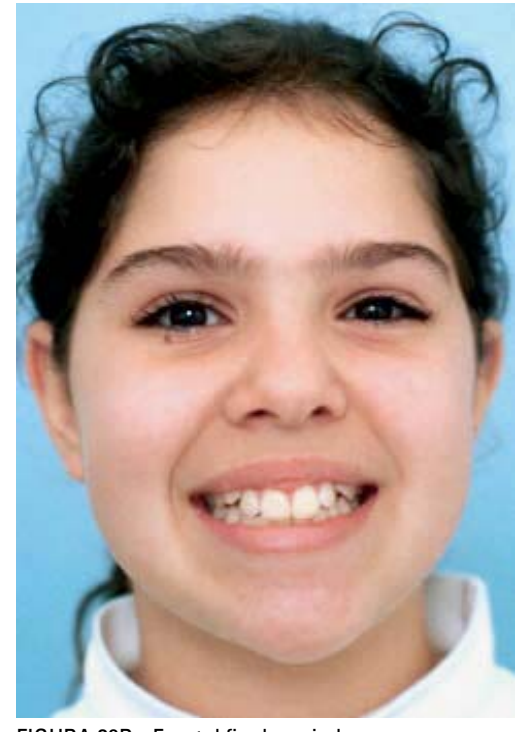

FIGURA 38B - Frontal final sorrindo.

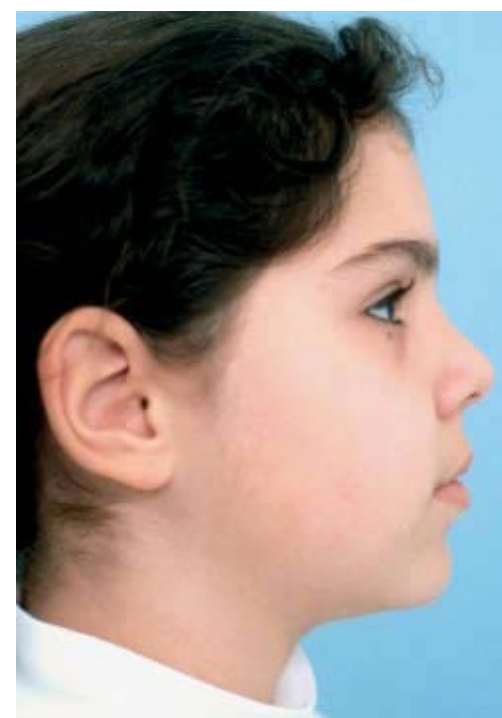

FIGURA 38C - Lateral final. primeiro molar superior. Entre a posição final e da previsão existe uma diferença de aproximadamente $2 \mathrm{~mm}$, determinada pela ação da BTP contra o crescimento vertical do processo alveolar, que é descrito por Stockli e Teuscher ${ }^{17,18}$ (Fig. 36). Clinicamente este resultado é mostrado nas figuras 34B e 35, com o fechamento da mordida aberta anterior.

3) No traçado de Ricketts temos um padrão braquifacial com índice Vert. de +0,59 (Fig. 37A).

4) $\mathrm{Na}$ análise do tecido mole através da Vertical Subnasal, houve a confirmação dos resultados anteriores com a melhora no posicionamento dos lábios e principalmente no mento, com a nítida rotação no sentido anti-horário (Fig. 37B).

5) Todos os resultados citados acima são confirmados na análise da face (Fig. 38A, B, C).

\section{CONCLUSÕES}

A BTP é um dispositivo mecânico que produz inúmeros movimentos e de acordo com os resultados obtidos especificamente neste trabalho, em pacientes que apresentam mordida aberta anterior com conseqüente comprometimento da harmonia facial, com retrusão e rotação da mandíbula no sentido horário é lícito concluir que:
1) A BTP pode ser utilizada para conseguir a rotação dos molares superiores com conseqüente ganho de espaço na arcada e diminuição ou até a correção da Classe II original.

2) A BTP pode provocar bloqueio do crescimento vertical do processo dentoalveolar ou até mesmo intrusão dos molares com conseqüente rotação espacial da mandíbula no sentido anti-horário, melhorando assim o relacionamento anterior tanto no sentido vertical como horizontal.

3) Com o uso da BTP podemos notar alteração na análise do tecido mole quando utilizamos a Vertical Subnasal.

Gostar do que se faz é um estado de espírito.

Trabalhar com amor e dignidade é uma responsabilidade.

Seguir princípios éticos e morais é um dever.

Procurar sempre a evolução científica é ir "em busca do ideal".

\section{J. A. Barbosa}




\title{
The transpalatal bar used for the mandibular rotation control
}

\begin{abstract}
Most of pacients in mixed dentition, with some open bite degree and atypical deglutition, we notice that the upper dentoalveolar process is increasing to the vertical side. The BTP use on the upper molar in these situations, with the central arch, low enough to make some pressure on the tongue during the deglutition. This system has been aproved as a molar intrusion movement. Can be noticed as a result the restriction of dentoalveolar process grown to the vertical side, orthopedic and jaw axes rotation grown in the horizontal direction changings.
\end{abstract}

Key words: Vertical control. Dentoalveolar process. Transpalatal arch. Intrusion. Class II maloclusion.

\section{REFERÊNCIAS}

1. AYALA, P. J.; GUTIERREZ, G. A. Tratamento da maloclusão de Classe II. In: INTERLANDI, S. Ortodontia: bases para a iniciação. 5. ed. São Paulo: Artes Médicas, 2002. cap.18, p. 330-376.

2. BARBOSA, J. A. Entrevista. R Clin Ortodon Dental Press, Maringá, v. 2, n. 3, p. 5-11, jun./jul. 2003.

3. BARBOSA, J. A. et al. Controle vertical do processo dento alveolar com o uso da Barra Transpalatina. RGo, Porto Alegre, v. 51, n. 4, out. 2003.

4. CARDOSO, M. A. Estudo das características cefalométricas do Padrão Face Longa. 2003. Dissertação (Mestrado) - Unesp, Araçatuba, 2003.

5. CETLIN, N. M.; HOEVE, A. T. Nonextraction treatment. J Clin Orthod, Boulder, v.17, no. 6, p. 396-413, June 1983.

6. CETLIN, N. M. Comunicação Pessoal. Curso de Ortodontia do Grupo Straight Wire em S.Paulo, 1998.

7. FERREIRA, C. C. Análise funcional da deglutição com e sem BTP. Trabalho de Conclusão de Curso (Especialização) - Centro de Estudos Odontológicos S. Leopoldo Mandic, Campinas, 2000.

8. MCNAMARA JR., J. A.; BRUDON, W. L. Tratamiento ortodóncico y ortopédico en la dentición mixta. Ann Arbor: Needham Press, 1995.

9. KANASHIRO, L. K.; FANTINI, S. M. Barra transpalatina no tratamento ortodôntico: Parte I. Ortodontia, São Paulo, v. 35, n. 2, p. 161-170, abr./jun. 2002.

10. KUCHER, G.; WEILAND, F. J. Goal-oriented positioning os upper second molars using the palatal intrusion technique. Am J Orthod Dentofacial Orthop, St. Louis, v.110, no. 5, p. 466-468, 1996.

11. LAMONS, F. F.; HOLMES, C. W. The problem of the rotated maxillary first permanent molar. Am J Orthod, St. Louis, v. 47, no. 4, p. 246-272, Apr. 1961.

12. MARCHI, L. C. et al. Considerações sobre a mecânica de Cetlin: relato de caso. $\mathbf{R}$ Clin Ortodon Dental Press, Maringá, v. 2, n.1, p. 37-44, fev./mar. 2003.

13. MCNAMARA JR., A. Transpalatal arches. In: ___ Integrated treatment os the orthodontic patient: diagnosis, treatment planning and clinical management. Ann Arbor: University of Michigan, 1986. cap. 7, p.1-9.

14. McNAMARA JR., A.; BRUDON, W. L. Orthodontic treatment in the mixed dentition. Ann Arbor: Needham Press, 1994. cap. 10, p. 179-192.

15. ROTH, R. H. Mecanica de tratamiento para el aparato de alambre recto. In: GRABER, T. M.; SWAIN, B. F. Ortodoncia: principios generales y tecnicas. Buenos Aires: Panamericana, 1988. cap.11, p. 763-825.

16. ROTH, R. H. Mecânica de tratamento para o aparelho Straight Wire. In: GRABER, T. M.; VANARSDALL, R. L. Ortodontia: princípios e técnicas atuais. Rio de Janeiro: Guanabara Koogan, 1996. cap.12, p. 636-660.

17. STÖCKLI, P. W.; TEUSCHER, U. M. Ortopedia combinada con activador y casquete. In: GRABER, T. M.; SWAIN, B. Ortodoncia: principios generales y tecnicas. Buenos Aires: Panamericana, 1988. cap. 7, p. 464-553.

18. STÖCKLI, P. W.; TEUSCHER, U. M. Ortopedia combinada com ativador e extrabucal. In: GRABER, T. M.; VANARSDALL, R. L. Ortodontia: princípios e técnicas atuais. Rio de Janeiro: Guanabara Koogan, 1996. cap. 8, p. 400-465.

19. SUZUKI, H. Avaliação cefalométrica da tendência da direção de crescimento da face, em posição natural da cabeça e horizontal verdadeira. 2001. Dissertação (Mestrado) - UCCB, Campinas, SP, 2001.

20. ZACHRISSON, B. Entrevista. R Dental Press Ortodon Ortop Facial, Maringá, v. 5, n. 2, p.1-6, mar./abr. 2000.

\author{
Endereço para correspondência \\ Jurandir A. Barbosa \\ Rua Abílio Figueiredo, 92, $12^{\circ}$ Andar - Centro \\ CEP: 13.208-140 - Jundiaí/SP \\ E-mail: ortodontia@jurandir.com.br
}

